\title{
TREACHER COLLINS SYNDROME - A RARE CONGENITAL DISORDER
}

Richa Gupta, Surendra Singh Moupachi, Shikha Gupta,Saurabh Gupta,Pallavi Gupta

1. Senior Resident. Department of ENT, S S Medical College. Rewa. Madhya Pradesh.

2. Associate Professor. Department of ENT, S S Medical College. Rewa. Madhya Pradesh.

3. Senior Resident. Department of Medicine, G. R. Medical College. Gwalior. Madhya Pradesh.

4. Post Graduate Student. Department of Medicine, S S Medical College. Rewa. Madhya Pradesh.

5. Post Graduate Student. Department of ENT, G. R. Medical College. Gwalior. Madhya Pradesh.

\section{CORRESPONDING AUTHOR:}

Dr. Richa Gupta,

D/O Mahesh Chand Gupta,

B.M. 31, Deendayal nagar,

Gwalior, Madhya Pradesh.

E-mail: dr_richa_tulip@yahoo.com

ABSTRACT: Treacher Collins syndrome (TCS) is a rare genetic disorder characterized primarily by abnormalities in the development of the head and face. We report a case of 5 year old boy who presented with complaint of hearing impairment and malformed pinna and later diagnosed as case of treacher Collins syndrome.

KEYWORDS: Coloboma . Congenital . TCOF1 gene, Treacher Collins syndrome

INTRODUCTION: Treacher Collins Syndrome, also known as Mandibulofacial dysostosis, is a rare genetic disorder characterized by craniofacial deformities [1]. In 1900, a British ophthalmologist named Edward Treacher Collins first described this birth defect [2]. It is estimated that Treacher Collins Syndrome occurs in 1 out of 50,000 births [3]. This syndrome is also known as Franceschetti-Klein syndrome and is caused by a mutation in the TCOF1 gene found at the 5q32-33.1 loci. It directly affects the development of the facial structures arising from the first and second brachial arches. Defects of the first arch arise around the $4^{\text {th }}$ week of development and are thought to occur from an insufficient migration of neural crest cells into the first arch, such is thought to be the case with Treacher Collins and Pierre Robin syndromes [4]. This occurs through an alteration of the encoding of the Treacle gene leading to variable hypoplasia and malformations of the facial bones. Diagnosis of Treacher Collins Syndrome is based on the clinical signs and symptoms. A geneticist can determine whether or not the syndrome was inherited [5].

CASE REPORT: We report a case of 5 year old boy who presented to department of ENT, S.S. Medical College, Rewa with the complaint of impairment of hearing and malformed pinna. On eliciting thorough detailed history it was revealed that patient mother had uneventful antenatal and postnatal period and delivered child by normal vaginal route at term. His milestones of development were age appropriate except hearing .On careful examination of the patient we observed wide palpebral fissure and coloboma in lateral part of both lower eyelids (Fig i). His eyes were remarkable for a downward obliquity of the palpebral fissures \& temporal notching of the lower lids. Also it was observed that patient had micrognathia, high arched palate, crowding of upper and lower teeth, bilateral microtia, bilateral preauricular sinus \& maxillary hypoplasia (Fig ii \& iii). His father also had milder form of this disorder which remained undiagnosed till date. 
$\mathrm{X}$ ray lateral cephalometric and occipitomental views were performed. Radiographic examination revealed underdeveloped condylar and coronoid processes, hypoplastic zygomatic arches \& maxillary hypoplasia (Fig iv \& v). However, the cranial vault and skull base appeared normal. Audiometry revealed severe degree of conductive hearing loss.

DISCUSSION: Treacher Collins Syndrome is a highly complex disease. Symptoms of this disorder vary greatly, ranging from almost unnoticeable to severe [6]. It is characterized by hypoplasia of the facial bones, especially the zygoma and the mandible. Facial clefting causes this hypoplastic appearance, with possible deformities or deficiencies of the ear, orbital, midface, and lower jaw regions [5, 7].

This syndrome is an example of an autosomal dominant syndrome with incomplete penetrance and variable expressivity [7]. An affected parent of either sex will transmit the defect to $50 \%$ of his or her offspring in accordance with mendelian laws of genetics. This emphasizes the importance of genetic counselling to affected individuals. It is common for mildly affected TCS patients to be diagnosed retrospectively after the birth of a more severely affected child [8]. This was similar to our case report where patient's father remained undiagnosed till his arrival in hospital.

Because the ramifications of this disorder are unrecognized, early diagnosis of the syndrome of mandibulofacial dysostosis is crucial. As the great majority of these patients are of normal intelligence, early recognition of deafness and its correction with hearing aids or surgery when possible is of great importance for development. The development of speech and language skills depends on the child's ability to hear during the first 3 years. Some children who have severe breathing difficulties require an operation to improve breathing and/or feeding. On the other hand, its psychological and social effects are devastating due to facial malformations. Therefore, it is imperative, that all dimensions of the syndrome must be given equal attention for appropriate treatment. In fact many features of the disease can be improved by surgery and other supportive treatments. A well planned treatment can produce excellent results for complete restoration of the forms and functions of the patient, enabling the individual to adapt to a "normal" way of life.

CONCLUSION: Each and every case of Treacher Collins Syndrome is unique and needs to be assessed individually. It is our responsibility as physicians to recognize this disorder, to be aware of both the classic and more subtle manifestations of this syndrome, and to provide close follow-up and appropriate therapy and counselling.

CONSENT: Written informed consent was obtained from the patient's father for publication of this case report and accompanying images.

\section{Funding: None \\ Conflict of interest: None}

\section{REFERENCES:}

1. A Franceschetti, D Klein. The mandibulo-facial dysostosis. A new hereditary syndrome. Acta Ophthalmologica J Craniofacial Surg 1949 ; 27: 143-224. 
2. Edwards SJ, Gladwin AJ, Dixon MJ. The mutational spectrum in Treacher Collins syndrome reveals a predominance of mutations that create a prematuretermination codon. Am J Hum Genet 1997; 60: 515-24.

3. Scriver CR. The metabolic \& molecular bases of inherited disease. Am J Pathol 2008; 173: 301-10.

4. Moore KL, Persaud TN. The Developing Human: Clinically Oriented Embryolog.8th ed. Philadelphia, PA: Saunders Elsevier; 2008.

5. Posnick JC, Ruiz RL. Treacher Collins syndrome: current evaluation, treatment, andfuture directions. Cleft Palate Craniofac J 2000; 37: 434

6. Farzana I, Afroza A, Rukunuzzaman MD, Rahman A, Hasan S. Treacher Collins syndrome - A case report. Bangladesh J Child Health 2008; 32:33-6

7. Thomson A. Notice of several cases of malformation of the external ear, together withexperiments on the state of hearing in such persons. London and Edinburgh Monthly Journalof Medical Science 1998; 7: 1846-47.

8. Trainor PA, Dixon J, Dixon MJ. Treacher Collins syndrome: Etiology, pathogenesis and prevention.Eur J Hum Genet 2009;17:275-83.
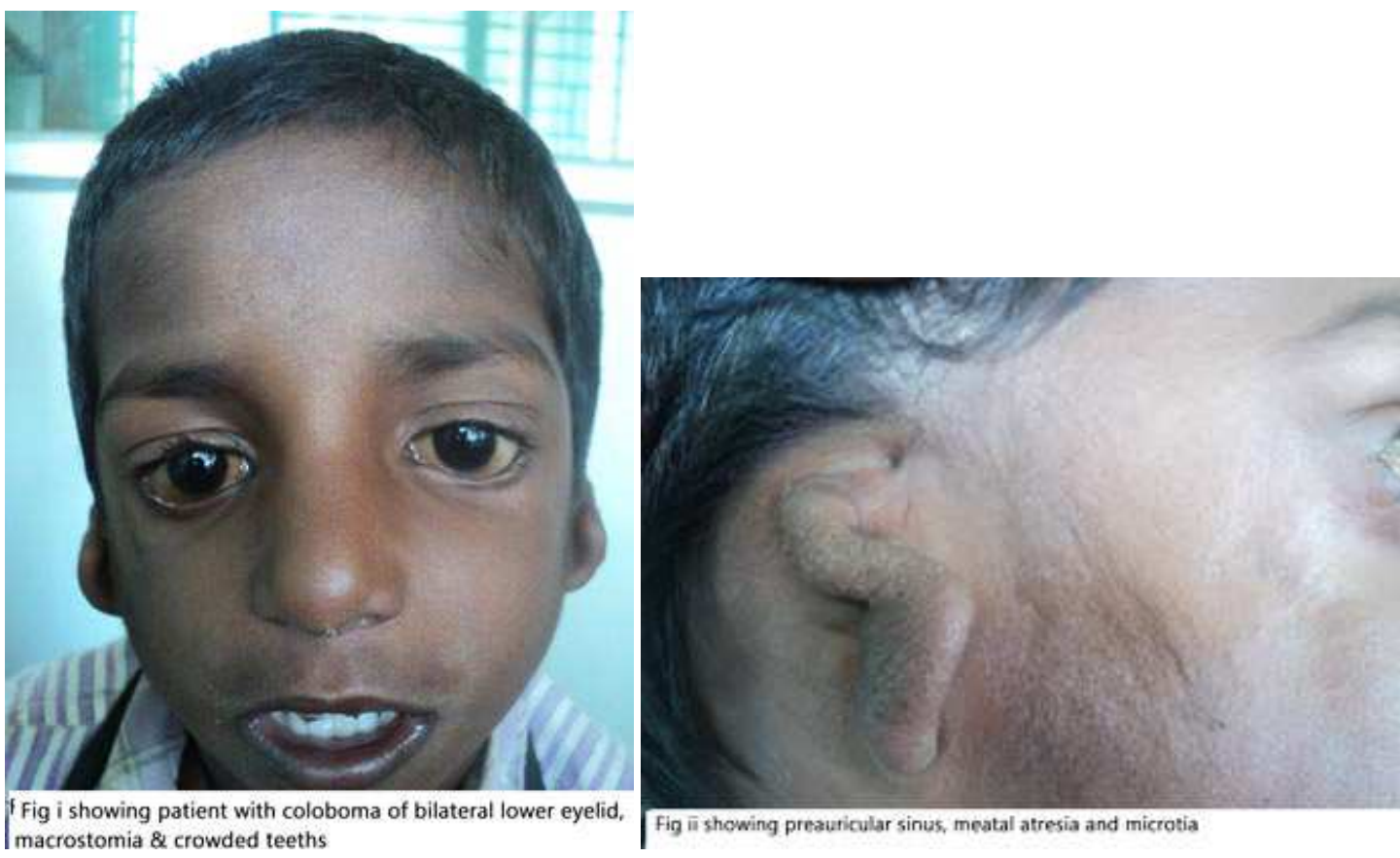


\section{CASE REPORT}
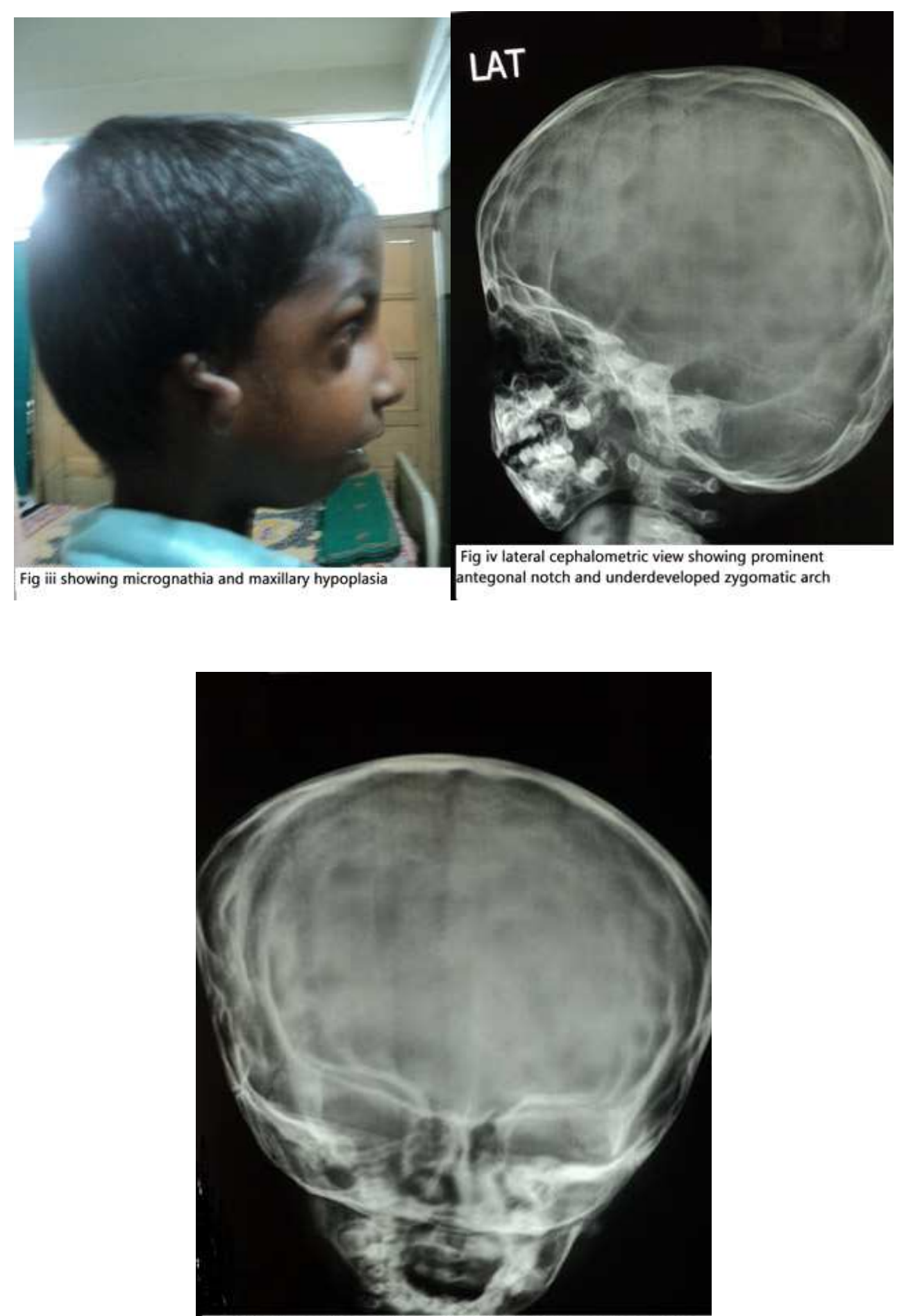

Fig (v) $\mathrm{X}$ ray anteroposterior view skull showing hypoplastic maxilla and zvnnmatir arrh 